\title{
Design and Technical Validation of a Telemedicine Service for Rural Healthcare in Ecuador
}

Leonel A. Vasquez-Cevallos, Patricia V. González-Granda, Enrique J. Gómez,
Jana Bobokova, José M. Iniesta, and M. Elena Hernando,

\section{Abstract}

Background: Telemedicine is becoming increasingly important in Ecuador, especially in areas such as rural primary healthcare and medical education. Rural telemedicine programs in the country need to be strengthened by means of a technological platform adapted to local surroundings and offering advantages such as access to specialized care, continuing education, and so on, combined with modest investment requirements.

Introduction: This present article presents the design of a Telemedicine Platform (TMP) for rural healthcare services in Ecuador and a preliminary technical validation with medical students and teachers.

Materials and Methods: An initial field study was designed to capture the requirements of the TMP. In a second phase, the TMP was validated in an academic environment along three consecutive academic courses. Assessment was by means of user polls and analyzing user interactions as registered automatically by the platform. The TMP was developed using Web-based technology and open code software.

Results: One hundred twenty-four students and 6 specialized faculty members participated in the study, conducting a total of 262 teleconsultations of clinical cases and 226 responses, respectively.

Conclusion: The validation results show that the TMP is a useful communication tool for the documentation and discussion of clinical cases. Moreover, its usage may be recommended as a teaching methodology, to strengthen the skills of medical undergraduates. The results indicate that implementing the system in rural healthcare services in Ecuador would be feasible.

Keywords: telemedicine, teleconsultation service, web-based technology, open source, rural healthcare, medical internship

\section{Introduction}

Temedicine makes it possible to improve patient healthcare, using Information and Communication Technologies (ICT) and telecommunication equipment to transfer information and give remote access to medical services. ${ }^{1,2}$ A component of telemedicine is teleconsultation between professionals, supported by the exchange of clinical information and videoconferencing, provided in rural areas where medical expertise is limited with access to specialized care.,4 Moreover, the use of teleconsultation application as a learning resource is described in several experiences in the literature. ${ }^{5,6}$ This telemedicine application is a useful teaching methodology for developing practicebased learning and clinical skills for the writing of case studies at all stages (students, graduates, and specialists). ${ }^{7}$ Training examples include telepathology, ${ }^{8}$ the teledermatology, ${ }^{9,10}$ and surgical training. ${ }^{11}$

Telemedicine is becoming increasingly important in Ecuador, especially in rural primary healthcare and medical education. However, Mijares ${ }^{12}$ identified the main barriers to widespread implantation of telemedicine in the country as poor connectivity and limited access to ICT, duplication of efforts between local institutions, and a lack of understanding of the benefits of telemedicine. Considering these limitations, the government of Ecuador has implemented a National Telemedicine/Telehealth program, which will provide Internet access and equipment to support Telemedicine applications in health institutions. ${ }^{13}$ Examples of experiences in rural Ecuador include Macas (Morona Santiago) with a videoconferencing system ${ }^{14}$ and Loja with the Tutupaly project. ${ }^{15}$

The Universidad Técnica Particular de Loja (UTPL) is a pioneer in the implementation of telemedicine services in rural areas, under the Tutupaly project, ${ }^{15}$ where the use and costs of exchanging clinical information between health professionals were evaluated. The project experience was conducted 
between entre 2007 and 2012, and its findings were the starting point for this present study. The project demonstrated the need to develop a telemedicine platform (TMP) integrating all communication tools and able to support the teleconsultation workflow: documental management of clinical cases, notifications, and the monitoring of user interactions.

This present article describes the design of a TMP to future support Tutupaly rural healthcare services and address a preliminary technical validation with medical students and teachers of UTPL.

\section{Materials and Methods}

\section{THE TUTUPALY PROJECT}

The Tutupaly project was implemented in collaboration with the Public Health Ministry of Ecuador. The participants were General Practitioners (GPs) enrolled with the Amazon rural area Mandatory Rural Service (MRS) and UTPL faculty doctors (FDs) who responded to the consultations submitted by GPs. Access to specialized knowledge and continuing education of MRS GPs were the principal objectives of the project.

Seven health posts (HPs) throughout the Yacuambi and El Pangui cantons (Fig. 1) in Zamora Chinchipe province participated in the project.

The project equipped all the HPs with a telecommunication network. Free ICT tools such as videoconference (Skype, Messenger), e-mail (Hotmail, institutional UTPL), and Internet Protocol (IP) telephony (Asterisk) were used to support inter- actions between users. Clinical cases and teleconsultation forms were exchanged using Microsoft Excel files.

\section{FUNCTIONAL AND TECHNICAL SPECIFICATIONS}

Martinez et al. ${ }^{16}$ evaluated a teleconsultation application in rural primary care in Peru and concluded that its usefulness may be extended to other countries throughout Latin America if teleconsultation services are tailored to local needs. The first step toward developing a telemedicine application is to define its functional specifications, including the hardware and software architecture specifications, taking into account organizational aspects, user profiles, and expectations. An exhaustive study of requirements contributes to optimal application performance, information reliability, usability, and user satisfaction. ${ }^{4,17,18}$

Identifying requirements. We visited three HPs which had participated in the Tutupaly project. A field study was addressed to identify the ICT tools and infrastructures in place at HPs; users' experience on ICT tools, Internet and telemedicine; and user expectations regarding the use of a TMP in the near future.

REVIEW OF ICT TOOLS. The three rural HPs analyzed were located in Yacuambi canton (28 de Mayo, La Esperanza, and Tutupali). The three HPs were connected to the Tutupaly telemedicine network, with a base station in the 28 de Mayo HP. UTPL sourced 128/64 Kbps connection from a local Internet provider. Each HP was supplied with a CPU, monitor, Webcam

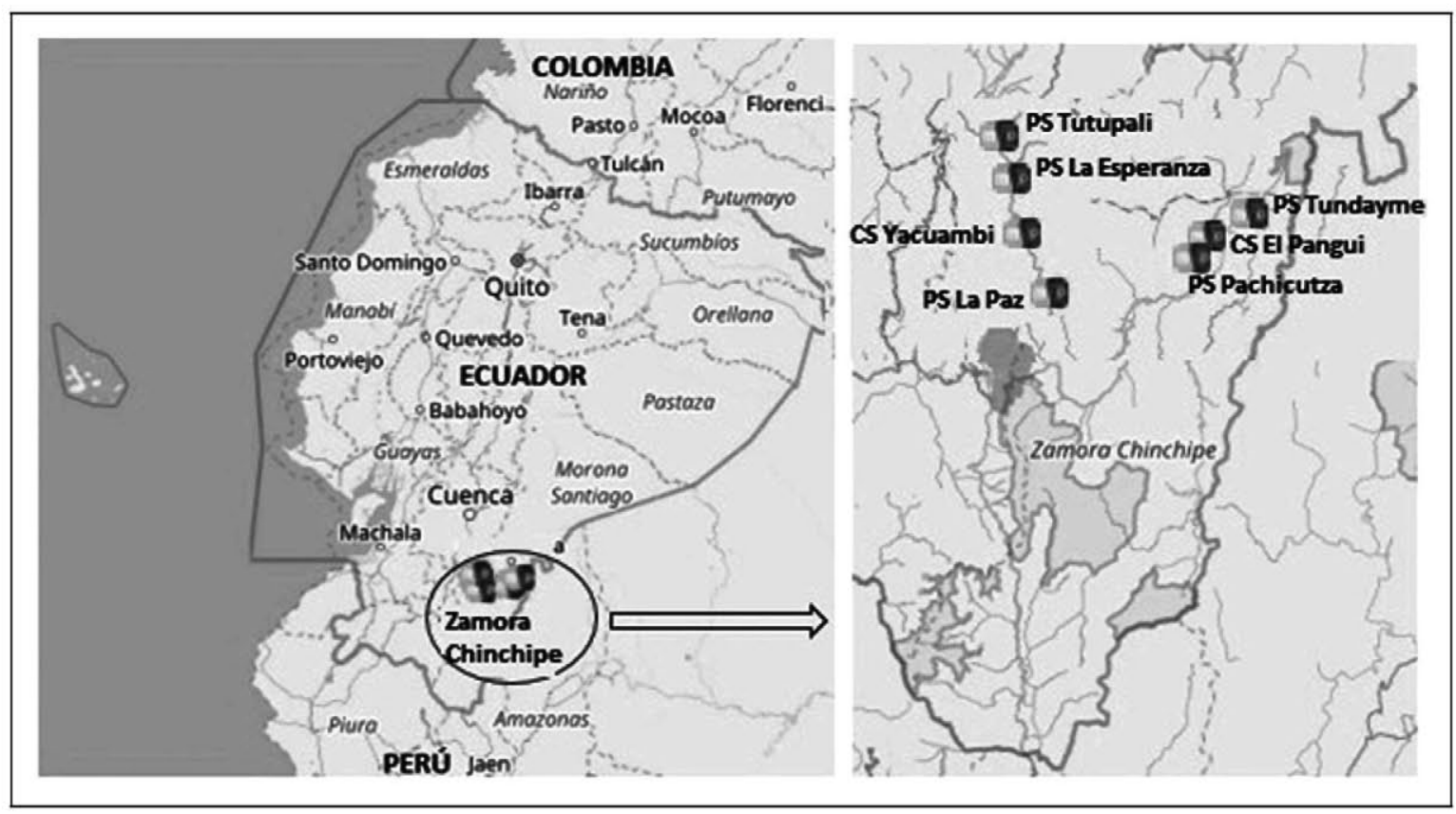

Fig. 1. Location of Tutupaly project health centers and posts. 
and microphone with speakers, and telecommunication equipment (a network Router Board, an analog telephone adaptor (ATA) IP telephony device, an analog telephone, and a wireless grid antenna). The 28 de Mayo also had an additional asymmetric digital subscriber line (ADSL) connection with Internet access (5/4 Mbps) provided by the National Government. Four MRS GPs were assigned to the HPs (one in Tutupali, two in 28 de Mayo, and one in La Esperanza).

A questionnaire was designed to collect information from users concerning: (1) previous experiences with ICT tools, Internet services, and telemedicine and (2) user expectations about the use of TMPs. The survey was performed in February 2013 with three user groups as follows: MRS GPs, the UTPL Medical Internship Coordinator, and FDs from UTPL. Table 1 shows the questionnaire. Questions were answered according to the Likert scale ${ }^{19}$ with a value between 1 and 5 representing low and high satisfaction levels, respectively. Table 1 gives the responses of the three groups.

Functional requirements and restrictions. The telemedicine application was required to support teleconsultations between faculty and MRS GP through asynchronous medical consultations, with electronic management of the clinical information.

Figure 2 shows the Unified Modeling Language (UML) use case diagram. MRS GPs fill in the clinical case form and send a consultation to the selected FD. The FD accesses the clinical case and creates a response. MRS GPs and FDs can review past teleconsultations and request for technical support. A tele-education module provides MRS GPs with telemedicine (TM) teaching resources. Administrators can access the technical support module, the management module, and the report module.

Technical Restrictions:

- The system is required to run on existing computers at the rural HP and at UTPL university. All Internet Web browsers should be supported, although Mozilla-Firefox is preferred.

- The platform must meet with data security requirements, and all clinical case documents and teleconsultation information must be stored in a local repository.

- Users must be able to connect to the platform from anywhere in the world, especially from rural areas provided with the UTPL network connection (128/64 Kbps) or the National Government connection (5/4 Mbps).

- The platform must be developed using open source software.

Technical specifications. A study of the minimum software and hardware requirements was made based on the results of sections (a) and (b). The results defined the: (1) infrastructure requirements (server and communications) and (2) software architecture.

Table 1. Previous Experience of and Expectations for Telemedicine (Average \pm Standard Deviation)

\begin{tabular}{l|l|l|l}
\hline QUESTIONS & MRS GP $(N=4)$ & MIC $(N=1)$ & FACULTY $(N=6)$
\end{tabular}

\begin{tabular}{|c|c|c|c|}
\hline P1. E-mail systems & $5.0 \pm 0.0$ & 5 & $5.0 \pm 0.0$ \\
\hline P2. Web and Internet applications & $5.0 \pm 0.0$ & 5 & $5.0 \pm 0.0$ \\
\hline P3. Computer applications for recording clinical data & $5.0 \pm 0.0$ & 5 & $5.0 \pm 0.0$ \\
\hline P4. Experience with Internet access in the workplace & $3.0 \pm 2.3$ & 5 & $5.0 \pm 0.0$ \\
\hline P5. Any application for direct teleconsultation between faculty and MRS GP? & $1.0 \pm 0.0$ & 2 & $3.0 \pm 2.2$ \\
\hline P6. Any application for direct teleconsultation between faculty and senior undergraduates? & $1.0 \pm 0.0$ & 1 & $1.0 \pm 0.0$ \\
\hline \multicolumn{4}{|l|}{ Usage expectations of telemedicine } \\
\hline $\begin{array}{l}\text { P7. Do you consider that telemedicine would help to increase interactions } \\
\text { between specialized faculty and MRS GP? }\end{array}$ & $5.0 \pm 0.0$ & 5 & $5.0 \pm 0.0$ \\
\hline $\begin{array}{l}\text { P8. Do you consider that telemedicine would help to increase interaction } \\
\text { between specialized faculty and senior undergraduates? }\end{array}$ & $4.5 \pm 0.6$ & 5 & $5.0 \pm 0.0$ \\
\hline P9. Do you consider that the system will be easy to use? & $5.0 \pm 0.0$ & 5 & $5.0 \pm 0.0$ \\
\hline P10. Do you consider that using the system will provide you with greater security? & $5.0 \pm 0.0$ & 5 & $5.0 \pm 0.0$ \\
\hline
\end{tabular}

MIC, medical internship coordinator; MRS GP, mandatory rural service general practitioner.

Score: $1=$ strongly disagree to $5=$ strongly agree. 


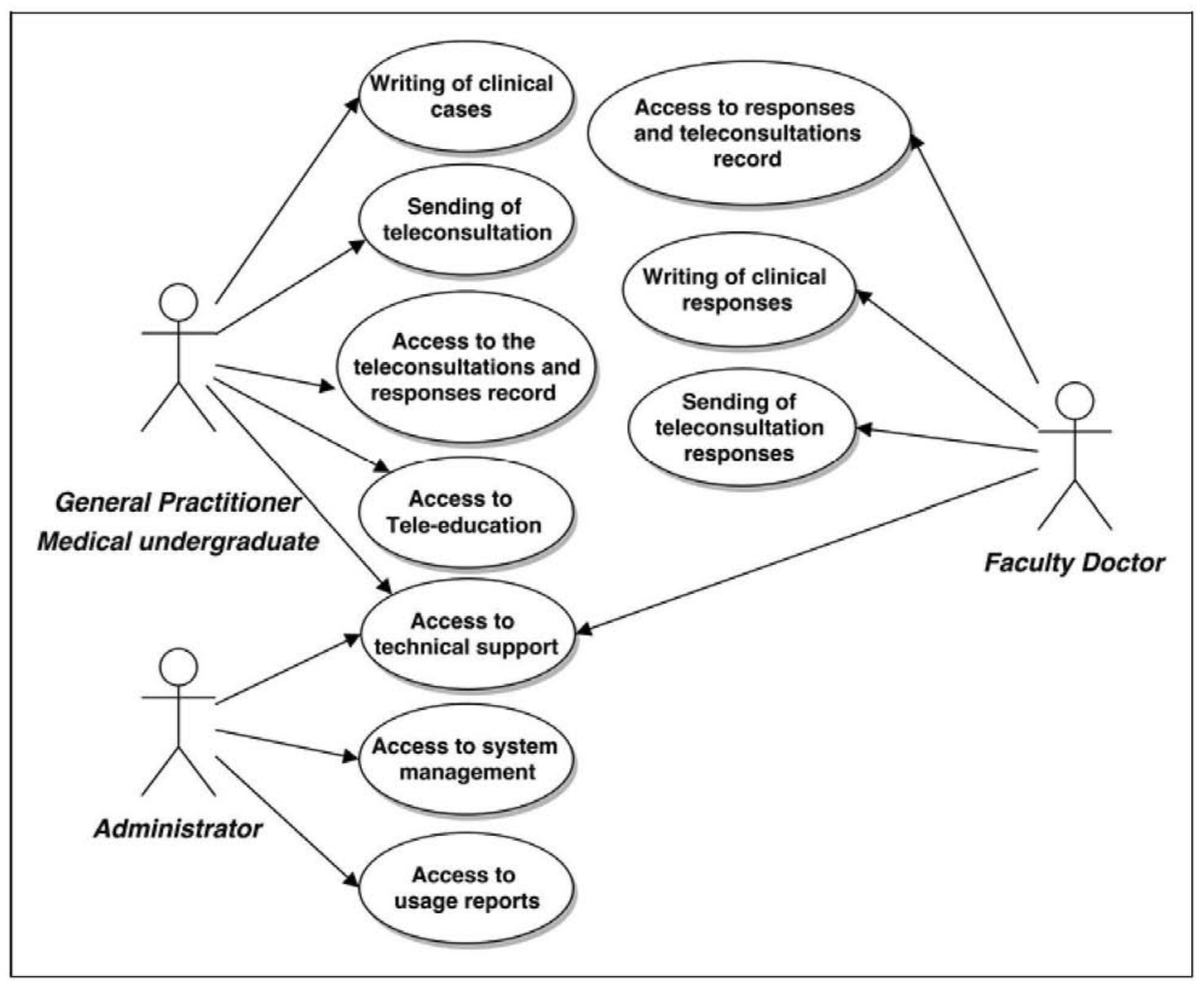

Fig. 2. Unified Modeling Language (UML) case diagram of the platform.

final decision was to install, configure, and customize the LAMP open source framework. LAMP is based on a Linux operating system (Ubuntu Server), Apache Web server with PHP code interpreter, and MySQL Database server. The telemedicine service was developed as a web application using Joomla framework, a license-free and open-source content management software framework. Joomla offers privacy, security, user-friendliness, and scalability. ${ }^{20}$ Moodle was the framework selected for the tele-education module.

Figure 3 shows the architecture of the TMP and the minimum requirements for the equipment and the communication connections.

\section{EVALUATION METHODOLOGY}

Description of the experience. The platform was validated by medicine faculty teachers and students. The TMP was used as a teaching resource in an elective course on telemedicine, offered as part of

SELECTED INFRASTRUCTURE. Server provided network domain services and web hosting (CPU P4 3 GHz, 1 GB RAM, 256 GB DDR); Internet-access bandwidth at least 20/13 Mbps server side and 128/64 Kbps user side.

SELECTED SOFTWARE ARCHITECTURE. Centralized client/server Web architecture with multiplatform access and low cost. The the Loja-Ecuador University undergraduate program. ${ }^{21}$ Students participating in the experiment were senior undergraduates, performing their internships in Teaching Assisting Units from hospitals or primary care centers of Loja. FDs had experience in clinical practice and teaching in a range of specialties, including internal medicine, family medicine, surgery, gynecology and obstetrics, general medicine, radiology, and pediatrics.

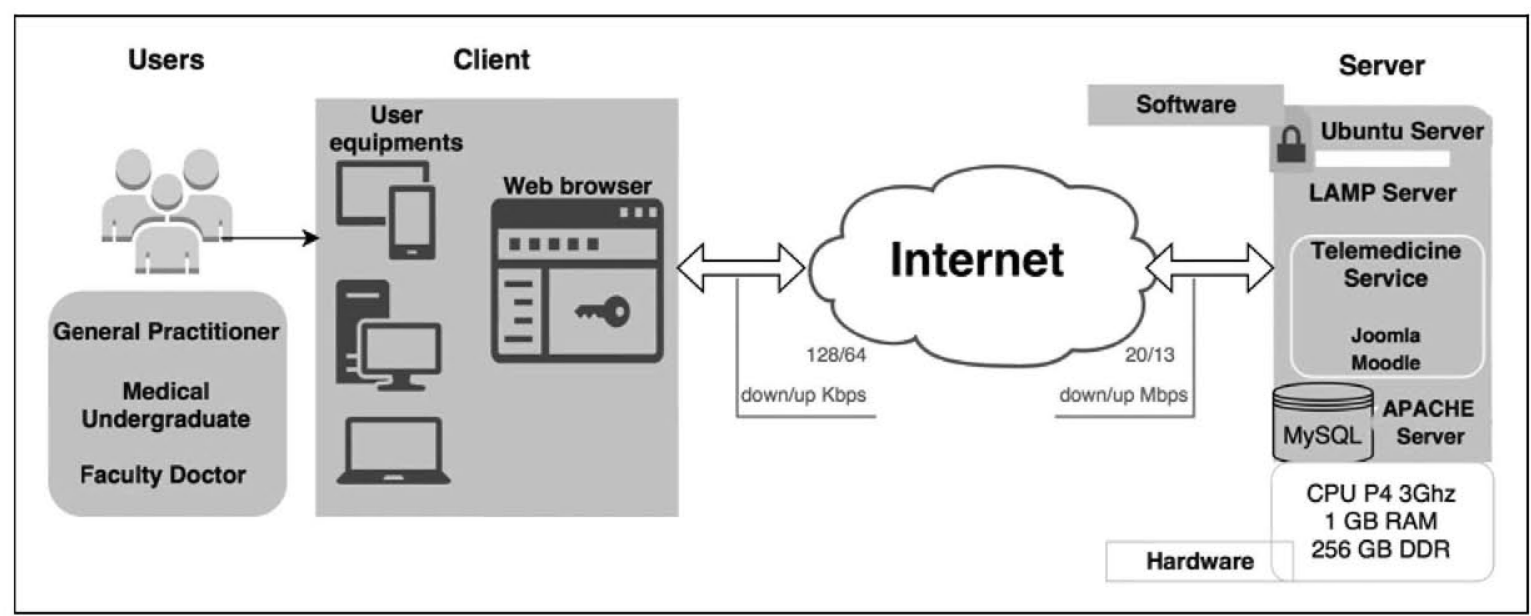

Fig. 3. TMP architecture and minimum requirements for equipment and communication connections. TMP, telemedicine platform. 


\begin{tabular}{l|c|c|c|c|c|c}
\multicolumn{2}{l|}{ Table 2. Usage Details } \\
$\begin{array}{l}\text { ACADEMIC } \\
\text { PERIODS }\end{array}$ & $\begin{array}{c}\text { NUMBER } \\
\text { OF STUDENTS }\end{array}$ & $\begin{array}{c}\text { NUMBER } \\
\text { OF TELECONSULTATIONS }\end{array}$ & $\begin{array}{c}\text { NUMBER } \\
\text { OF ANSWERS }\end{array}$ & $\begin{array}{c}\text { TC WRITING } \\
\text { TIME (MIN) }\end{array}$ & $\begin{array}{c}\text { RT WRITING } \\
\text { TIME (MIN) }\end{array}$ & $\begin{array}{c}\text { RT WAITING } \\
\text { TIME (DAYS) }\end{array}$ \\
\hline Period 1 & 50 & 53 & 45 & $24.8 \pm 15.4$ & $14.1 \pm 6.1$ & $6.2 \pm 5.8$ \\
\hline Period 2 & 40 & 123 & 111 & $28.0 \pm 13.6$ & $12.0 \pm 5.7$ & $8.4 \pm 11.2$ \\
\hline Period 3 & 34 & 86 & 70 & $32.0 \pm 15.8$ & $8.8 \pm 4.4$ & $3.8 \pm 1.5$ \\
\hline Total & 124 & 262 & 226 & $28.3 \pm 15.0$ & $11.6 \pm 5.4$ & $6.1 \pm 6.2$ \\
\hline
\end{tabular}

$R T$, response to teleconsultation; SD, standard deviation; $T C$, teleconsultation.

Students were required to create a clinical case, sending a teleconsultation to a specialist of their choice. Using their access credentials, students logged in to the platform, from any Web browser, creating the clinical case and completing the teleconsultation form. The teleconsultation documentation contains information established for the electronic medical record (Tutupaly project teleconsultation form): reason for the consultation, current illness, medical history, physical examination, tests performed, and probable diagnoses. ${ }^{22}$ Users also had the option of adding comments or questions and attaching additional files, such as images. Courses had a duration of 4 months, with students being asked to send 1 monthly teleconsultation, giving a total of four per student. Teaching specialists were asked to send their responses within $24 \mathrm{~h}$ after being notified by the platform through e-mail. The response form includes comments on the symptoms, proposed diagnostic tests, presumptive or definitive diagnoses, proposed treatment, and the proposed education plan.

Evaluation method. Previous experiences have identified standard benchmarks and suggestions for evaluating telemedicine systems, although no evaluation model has been widely implemented. ${ }^{23,24}$

In our study, we evaluate the effectiveness, reliability, usability, and usage of the TMP by means of auto-generated records of user interactions with the platform and questionnaires filled in by users (doctors and students), designed following the criteria developed in previous experiences. ${ }^{16,25-28}$

AUTO-GENERATED USAGE RECORDS. The parameters for analyzing the use of the TMP included total number of teleconsultations and responses; time spent writing teleconsultations ( $\mathrm{min})$; time spent writing response $(\mathrm{min})$; and teleconsultation waiting time (days). The parameters were automatically registered by the platform, with total user transparency. The mean values of each parameter and its standard deviation were calculated for each global period and for each month of the study.
FEASIBILITY AND ACCEPTANCE EVALUATION. FDs responded to one initial questionnaire (Table 1) and one final questionnaire at the end of the evaluation experiment (Table 2). The final questionnaire consists of 10 questions: 2 related to task effectiveness; 3 concerning reliability; 2 on usability; and 3 on acceptability and usage satisfaction. Questions were answered using the Likert scale. ${ }^{19}$

At the end of each course, students answered a final questionnaire of four questions, ${ }^{29}$ three being open questions on utility (Q1), advantages (Q2), and disadvantages (Q3) of the platform and the fourth (Q4) on whether they would use the platform during their MRS after graduation. For further quantitative analysis, the answers to the first three questions were coded as short answers, similar to the work of Popping. ${ }^{30}$

\section{Results}

The study was conducted along three consecutive academic courses, each with a duration of 4 months. It covered six teachers, each with more than 5 years of experience in clinical practice and teaching, and 124 students.

\section{AUTO-GENERATED USAGE RECORDS}

Table 2 shows TMP usage along the three test periods. Students spent an average of $28.3 \mathrm{~min}$ writing cases; FDs spent an average of $11.6 \mathrm{~min}$ writing responses.

On average, FDs response time (6.1 days) was much longer than recommended $(24 \mathrm{~h})$ and also varied widely ( $\min 0.1$ days to max 12.3 days).

Figure 4 shows the distribution of teleconsultation submissions over the months. Certain peaks are observed mainly coinciding with the end of academic periods. These peaks had an impact on the number of unanswered teleconsultations $(8,12$, and 16 , respectively, over the periods).

\section{FEASIBILITY AND ACCEPTANCE}

A majority, 83\% (5/6) of the FDs participating in this study, completed the final questionnaire. Figure 5 shows the average 


\section{VASQUEZ-CEVALLOS ET AL.}

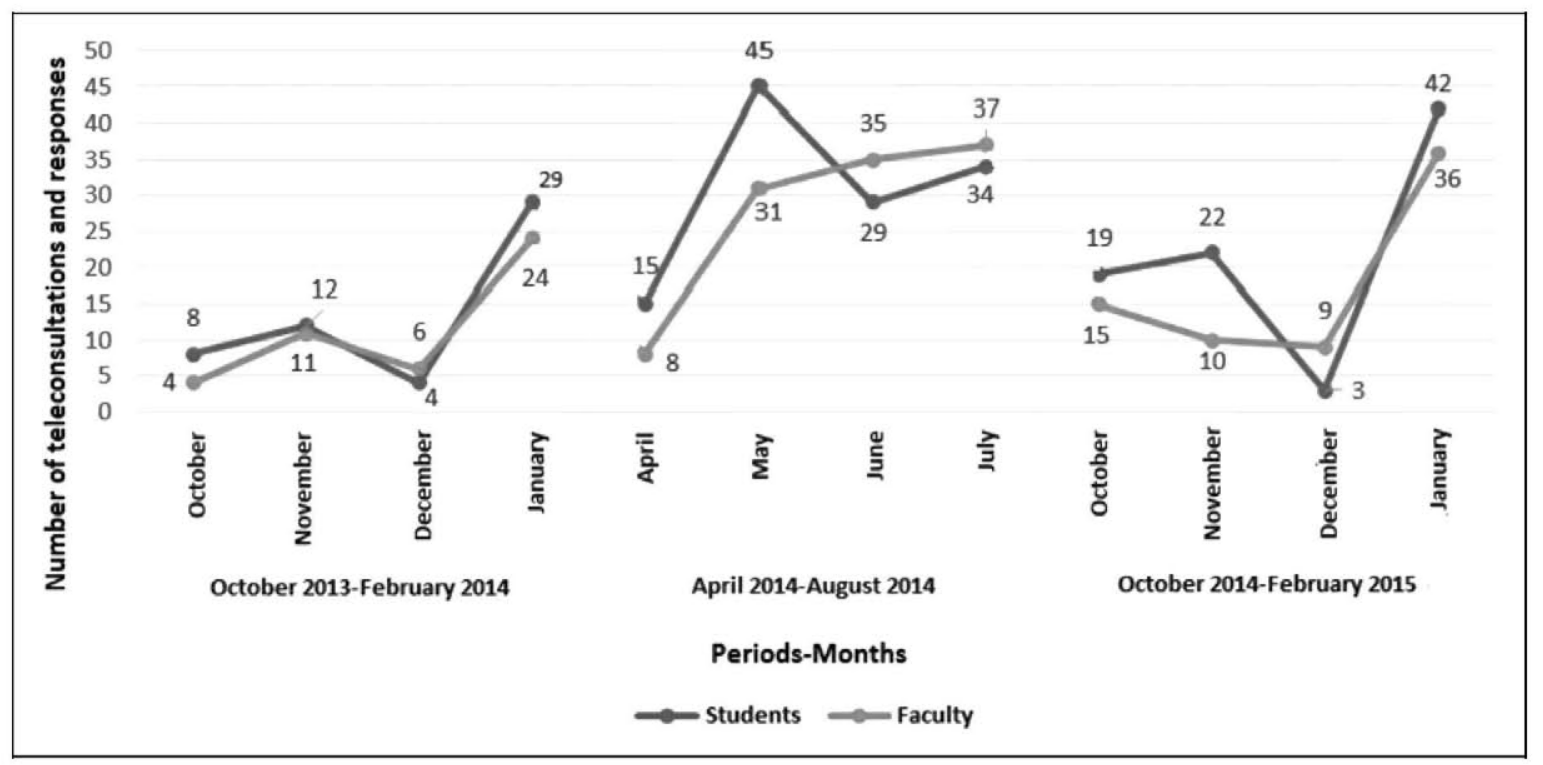

Fig. 4. Monthly distribution of teleconsultations and answers.

value of responses to the questionnaire, with regard to task effectiveness, reliability, usability, and acceptation. All FDs strongly agreed on the effectiveness of the platform, expressed a high degree of acceptance and satisfaction, and considered the platform useful for undergraduate medical training and for mandatory Rural Medical Service. The platform was rated as being reliable, as well as being user-friendly and easy to learn. All respondents strongly recommend the use of the TMP to support teleconsultations.

A majority, 51\% (63/124) of the students who participated in this study, completed the questionnaire. All the survey respondents $(63 / 63)$ considered the platform to be useful for the learning process. The main advantages indicated by students included increased access to specialists, enhanced practical knowledge, and assistance in the diagnosis and treatment processes. The main disadvantage they identified was the delay in answering the teleconsultation by faculty (Fig. 6). Only $11 \%$ of survey respondents experienced failures with platform connections or Web browser crashes when using the tool. All students surveyed responded that they would use the platform in their rural service.

\section{Discussion}

The TMP architecture offers direct communication between FDs and students. The selection of an open-source software

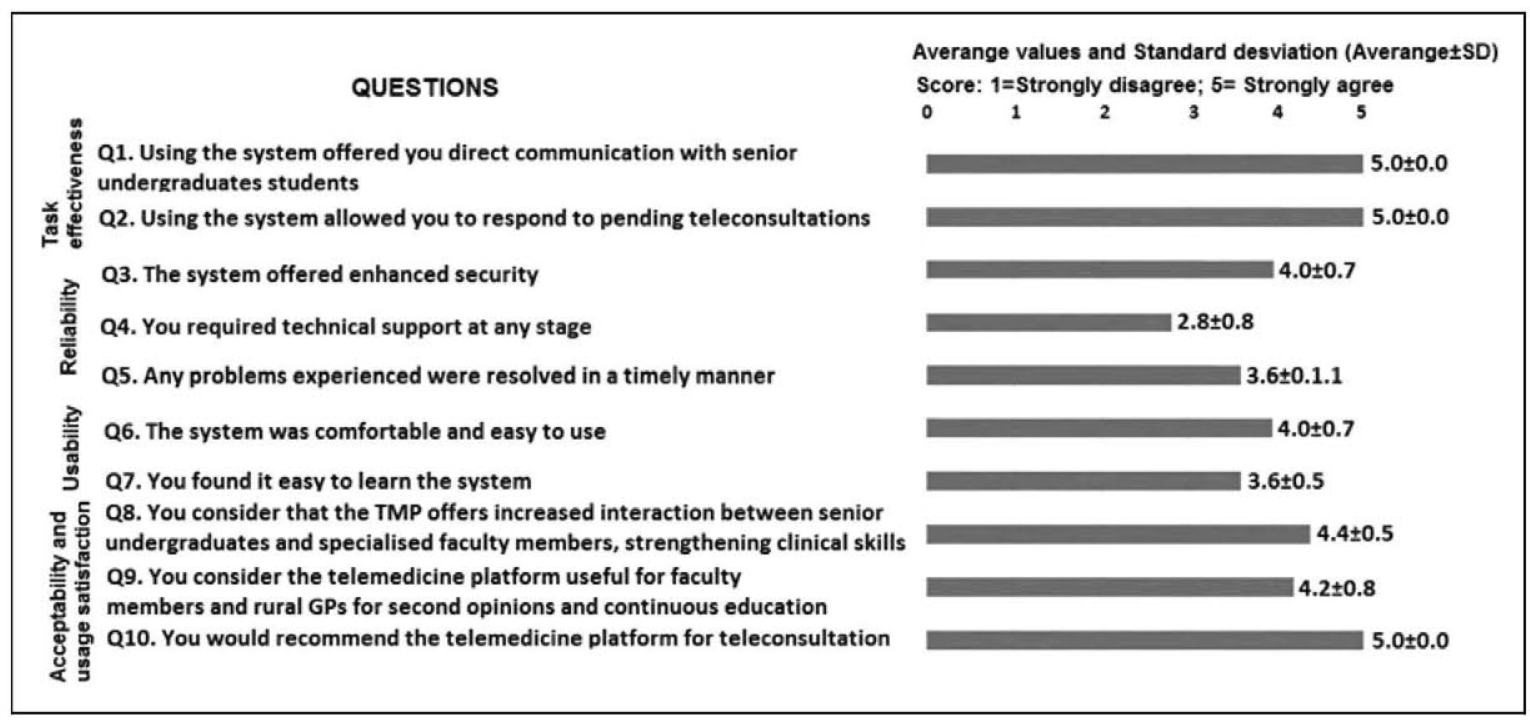

Fig. 5. Faculty answers after validation of the TMP $(n=5)$. 


\section{TELEMEDICINE FOR RURAL HEALTHCARE IN ECUADOR}

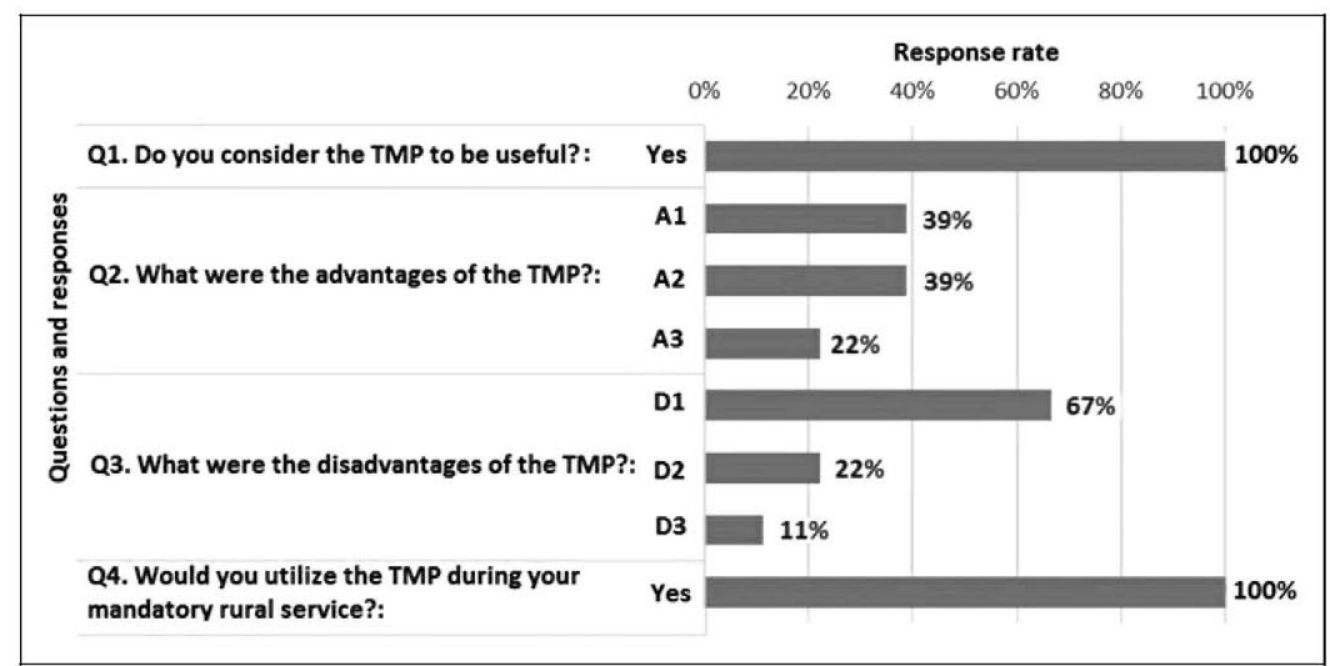

Fig. 6. Students' answers $(n=63)$ : Q1. Utility; Q2. Advantages, A1: Increased access to specialists, A2: Enhanced practical knowledge, A3: Assistance in the diagnosis and treatment processes; Q3. Disadvantages, D1: No disadvantage, D2: The delay in answering the teleconsultation, $\mathrm{D}_{3}$ : Web browser crashes; and Q4. Usage in rural service.

infrastructure guarantees permanent upgrades and support from the community, ${ }^{6}$ offering reduced maintenance costs compared to commercial software. Current usage figures, such as the clinical case writing time and response writing time, will serve as a reference for internship coordinators and FDs for organizing academic activities and planning faculty workloads. ${ }^{19}$

The results of the evaluation indicate that the TMP is acceptable and feasible for senior undergraduates. FDs indicated that TMP is a useful tool to support rural healthcare services, and all students declared their intention to use the platform during their MRS.

One limitation on the study is the small teacher sample (5/6), which does not favor the generalization of results. However, there is a broad consensus among participants, particularly faculty, regarding the efficiency, reliability, usability, and utility of the platform in the acquisition of practical knowledge, as evidenced by the low variability in responses; accordingly, an increase in sample size would likely not influence results. A second limitation of the study is the difference in student numbers in each period. However, the same methodology was followed in each period.

In the future, we propose a series of studies involving even more rural HPs, specialists, and hospitals, with the aim of demonstrating the impact of telemedicine on rural healthcare and medical internship situations at national level, as required by the National Accreditation and Evaluation Body. ${ }^{31}$

\section{Conclusions}

The validation results show that TMP is a useful communication tool for the documentation and discussion of clinical cases and that it can be recommended to strengthen undergraduate medical practice programs. They also show that implementing the system in rural healthcare services in Ecuador would be feasible.

\section{Acknowledgments}

The authors thank UTPL teachers and students for their collaboration in the validation experiment. This research has been partially financed by the Ecuador Secretary SENESCYT in the Doctoral Program in Biomedical Engineering at UPM University.

\section{Disclosure Statement}

No competing financial interests exist.

\section{REFERENCES}

1. World Health Organization. Telemedicine: Opportunities and developments in member states. Available at www.who.int/goe/publications/ goe_telemedicine_2010.pdf (last accessed October 15, 2016).

2. Davis TM, Barden C, Dean S, Gavish A, Goliash I, et al. American Telemedicine Association Guidelines for TeleICU operations. Telemed J E Health 2016;22: 971-980.

3. Wootton R. Telemedicine and developing countries: Successful implementation will require a shared approach. J Telemed Telecare 2001;7:1-6.

4. Nerlich M, Balas EA, Schall T, Stieglitz SP, Filzmaier R, Asbach P, Doarn CR. Teleconsultation practice guidelines: Report from $\mathrm{G} 8$ global health applications subproject 4. Telemed J E Health 2002;8:411-418.

5. Nicholson RS, Bassham L, Chapman A, Fricker D. Using teleconsultation for collaboration between occupational therapy fieldwork and academic settings. Technol Spec Interest Sect Q 2014;24:1-4.

6. Sánchez-González P, Burgos D, Oropesa I, Romero V, Albacete A, SánchezPeralta LF, et al. TELMA: Technology-enhanced learning environment for minimally invasive surgery. J Surg Res 2013;182:21-29. 


\section{VASQUEZ-CEVALLOS ET AL.}

7. Mangrulkar $\mathrm{R}$, Athey $B$, Brebner $E_{1}$ Moidu $K$, Pulido $P$, Woolliscroft J. Telemedicine/telehealth: An international persoective. Telemedicine and medical/health education. Telemed J E Health 2002;8:49-60.

8. Gongora $\mathrm{JH}$, Barcelo HA. Telepathology and continuous education: Important tools for pathologists of developing countries. Diagn. Pathol 2008;3:\$24.

9. Berghout RM. Evaluation of general practitioner's time investment during a store-and-forward teledermatology consultation. Int J Med Inform 2007;76: S384-S391.

10. Boyers LN, Schultz A, Baceviciene R, Blaney S, Marvi N, Dellavalle RP. Teledermatology as an educational tool for teaching dermatology to residents and medical students. Telemed J E Health 2015;21:312-314.

11. Mora $F$, Cone $S$, Rodas $E_{1}$ Merrell RC. Telemedicine and electronic health information for clinical continuity in a mobile surgery program. World J Surg 2006;30:1128-1134.

12. Mijares M. Limitaciones para la implementación de proyectos de telemedicina $y$ eSalud basado en la experiencia ecuatoriana. eSalud 2007:3:3-11.

13. Lopez $R$, Vilela $L$, Fernández $G$. Programa Nacional de Telemedicina/Telesalud Equador. Latin Am J Telehealth 2012;2:3-2.

14. Cone SW, Hummel R, León J, Merrell RC. Implementation and evaluation of a low-cost telemedicine station in the remote Ecuadorian rainforest. $J$ Telemed Telecare 2007:13:31-34.

15. Rios-Ramirez AX. Análisis costo-beneficio del proyecto TELESALUD UTPLTUTUPALY [Medicine degree Dissertation] Yacuambi-Ecuador 2010; 93. Available at http://dspace.utpl.edu.ec/handle/123456789/1635 (last accessed October 15, 2016)

16. Martinez A, Villarroel V, Seoane J, Del Pozo F. A study of a rural telemedicine system in the Amazon region of Peru. $J$ Telemed Telecare 2004:10:219-225.

17. Ohinmaa $A_{1}$ Hailey $D_{1}$ Roine R. Elements for assessment of telemedicine applications. Int J Technol Assess Health Care 2001;17:190-202

18. Zangara G, Valentino $F$, Spinelli G, Valenza M, Marcheggiani A, Di Blasi F. An Albanian open source telemedicine platform. Telemed J E Health 2014;20: 673-677.

19. Doll WJ, Torkzadeh G. The measurement of end-user computing satisfactionTheoretical and methodological issues. MIS O 1991;15:5-10

20. Patel SK, Rathod VR, Prajapati JB. Performance analysis of content management systems-joomla, drupal and wordoress. Int J Comput Appl 2011;21:39-43.

21. Universidad Técnica Particular de Loja (UTPL). The telemedicine course olan. Available at www.utpl-telesalud.gbt.tfo.upm.es/Plan_Docente_abril-agostoGonzalez_Granda.pdf (last accessed November 13, 2016).

22. Ministerio de Salud Pública de Ecuador. Expediente único para la Historia Clinica. Available at www.conasa.gobed/codigo/publicaciones/hcul historia_clinica.pdf (last accessed November 13, 2016)
23. Puskin DS, Cohen $Z_{1}$ Ferguson AS, Krupinski $E_{1}$ Soaulding $R$, Implementation and evaluation of telehealth tools and technologies. Telemed J E Health 2010; $16: 96-102$.

24. Khanal S, Burgon J, Leonard S, Griffiths M, Eddowes LA. Recommendations for the improved effectiveness and reporting of telemedicine programs in developing countries: Results of a systematic literature review. Telemed $J E$ Health 2015;21:903-915

25. Holle $\mathrm{R}$, Zahlmann G. Evaluation of telemedical services. IEEE Trans Inf Technol Biomed 1999;3:84-91.

26. Zanaboni P, Scalvini S, Bernocchi P, Borghi G, Tridico C, Masella C. Teleconsultation service to improve healthcare in rural areas: Acceptance, organizational impact and appropriateness. BMC Health Serv Res 2009;9:238.

27. Saiǵı F. Aprendizaje colaborativo en red: El caso Del Laboratorio de Telemedicina. Gac Sanit 2011;25:254-256

28. Hu PJ, Chau PYK, Sheng ORL. Examining the technology acceptance model using physician acceptance of telemedicine technology. J Manag Inf Sys 1999; $16: 91-112$.

29. Granda-González PV, Sinche-Gutierrez NA. Uso de una plataforma de telemedicina para el fortalecimiento de competencias clinicas. Opción 2016;32-39

30. Popping R. Analyzing open-ended questions by means of text analysis procedures. Bull Méthodol Sociol 2015;128:23-39

31. Consejo de Evaluación, Acreditación y Aseguramiento de la Calidad de la Educación Superior (CEAACES). Informe definitivo de evaluación del entorno de aprendizaje de la carrera de medicina. Available at www.ceaaces.gob.ec/sitio/wpcontent/uploads/2014/08//nforme-definitivo-de-evaluacion-del-entorno-deaprendizaje-de-la-carrera-de-medicina.pdf (last accessed November 13, 2016) 